\title{
A cloud detection algorithm using the downwelling infrared radiance measured by an infrared pyrometer of the ground-based microwave radiometer
}

\author{
M.-H. Ahn ${ }^{1}$, D. Han ${ }^{1}$, H. Y. Won ${ }^{1}$, and V. Morris ${ }^{2}$ \\ ${ }^{1}$ Department of Atmospheric Science and Engineering, Ewha Womans University, Ewha-Yeodae-Gil 52, \\ Seodaemoon-Gu, Seoul, South Korea \\ ${ }^{2}$ Pacific Northwest National Laboratory, Richland, Washington, USA \\ Correspondence to: M.-H. Ahn (terryahn65@ewha.ac.kr)
}

Received: 2 July 2014 - Published in Atmos. Meas. Tech. Discuss.: 16 September 2014

Revised: 31 December 2014 - Accepted: 10 January 2015 - Published: 3 February 2015

\begin{abstract}
For better utilization of the ground-based microwave radiometer, it is important to detect the cloud presence in the measured data. Here, we introduce a simple and fast cloud detection algorithm by using the optical characteristics of the clouds in the infrared atmospheric window region. The new algorithm utilizes the brightness temperature $(\mathrm{Tb})$ measured by an infrared radiometer installed on top of a microwave radiometer. The two-step algorithm consists of a spectral test followed by a temporal test. The measured $\mathrm{Tb}$ is first compared with a predicted clear-sky $\mathrm{Tb}$ obtained by an empirical formula as a function of surface air temperature and water vapor pressure. For the temporal test, the temporal variability of the measured $\mathrm{Tb}$ during one minute compares with a dynamic threshold value, representing the variability of clear-sky conditions. It is designated as cloudfree data only when both the spectral and temporal tests confirm cloud-free data. Overall, most of the thick and uniform clouds are successfully detected by the spectral test, while the broken and fast-varying clouds are detected by the temporal test. The algorithm is validated by comparison with the collocated ceilometer data for six months, from January to June 2013. The overall proportion of correctness is about $88.3 \%$ and the probability of detection is $90.8 \%$, which are comparable with or better than those of previous similar approaches. Two thirds of discrepancies occur when the new algorithm detects clouds while the ceilometer does not, resulting in different values of the probability of detection with different cloud-base altitude, 93.8, 90.3, and $82.8 \%$ for low, mid, and high clouds, respectively. Finally, due to the char-
\end{abstract}

acteristics of the spectral range, the new algorithm is found to be insensitive to the presence of inversion layers.

\section{Introduction}

Ground-based remote sensing instruments such as the microwave sounding radiometer for the acquisition of vertical profiles of temperature and humidity have long been considered as candidates to replace conventional observations, offering potential advantages in cost efficiency, temporal resolution, and spatial coverage ( $\mathrm{Li}$ et al., 1997; Solheim et al., 1998; Löhnert and Maier, 2012). For better utilization of data from these instruments, not only is the acquisition of accurate and reliable measurement data critically important, but also the characterizations of the measurement data. One of the frequently used methods for characterizing the measured brightness temperature $(\mathrm{Tb})$ of a ground-based microwave radiometer is to compare it with simulated theoretical values (Liljegren and Lesht, 1996; Cimini et al., 2003; Löhnert and Maier, 2012). However, one condition which is neither usually obtained, nor treated correctly either by observation or simulation, and also introduces a significant uncertainty in the theoretical simulation, is cloudy conditions. Usually, the presence of clouds with even a small optical depth increases downwelling radiation, and thus introduces significant uncertainties in the comparison results, especially at the higher frequency channels (Cadeddu and Turner, 2011). 
The presence of clouds also affects the retrieval accuracy of the vertical profiles of temperature and humidity (Han and Westwater, 1995; Hewison, 2007), cloud liquid water, and precipitable water vapor (Solheim et al., 1998; Turner, 2007; Löhnert et al., 2008). This is mainly due to the disparate cloud effects on the downwelling radiance at the different frequencies, being more prominent at the window bands than at the absorption bands and decreasing with increasing frequency. To mitigate this effect, multi-sensor approaches are commonly used (Crewell and Löhnert, 2003; Turner, 2007; Gaussiat et al., 2007), which take advantage of the differential optical response of clouds with additional instruments such as the ceilometer and cloud radar (Han and Westwater, 1995; Gaussiat et al., 2007; Löhnert et al., 2008). However, for a certain situation where the additional instruments are not available or the collocation of the multi-sensor data is difficult, there is no other choice than to use data from only a single instrument. Further, when the additional instruments have uncertainties in the calibration, the need for an independent algorithm increases. Indeed, the microwave radiometer used for the current study lacks additional instruments for cloud detection for a large portion of the available data and thus an independent algorithm is highly desired.

Here, we introduce an algorithm using the downwelling radiance measured by the infrared radiometer (IRT), an optional instrument installed on top of the microwave radiometer (RPG, 2013), together with the surface air temperature $\left(T_{\mathrm{sfc}}\right)$ and the surface water vapor pressure $(e)$ data obtained at $2 \mathrm{~m}$ above the ground. The possibility of cloud detection using downwelling infrared radiation has long been demonstrated either by using total irradiance (Brutsaert, 1975; Marty and Philipona, 2000; Dürr and Philipona, 2004), narrow band radiance (Thurairajah and Shaw, 2005; Feister et al., 2010; Brocard et al., 2011; Klebe et al., 2014), or by multi-spectral radiance (Turner and Gero, 2011; Gero and Turner, 2011). Regardless of approach, the background physics for the cloud detection is that the atmospheric emissivity in the infrared window regions is much smaller than that of clouds. Thus, even with optically thin clouds, the downwelling radiation could increase significantly and the cloud detection could be relatively straightforward.

However, depending on the approach, there are certain limitations and difficulties. For example, the total irradiance approach is not capable of detecting the high clouds because of the weak sensitivity in the total irradiance to the high clouds (Ohmura, 2001; Dürr and Philipona, 2004). On the other hand, this approach could falsely identify clear sky as a cloudy sky when there is a strong inversion layer at the lower atmosphere (Sutter et al., 2004). The thin cirrus problem in the total irradiance approach also occurs in the narrow band approach, and thus Brocard et al. (2011) use the temporal variability of the measured radiance to overcome this limitation. Another issue with the narrow band approach is that non-cloud features such as a thick aerosol or haze can be falsely detected as a cloud. Thus, a dynamic threshold ap- proach using auxiliary data has been applied for better cloud detection (Thurairajah and Shaw, 2005). Even in the case of multi-spectral radiance, thin high clouds with a humid atmosphere are known to be difficult to correctly detect (Turner and Gero, 2011).

Thus, the new algorithm utilizes both the spectral and the temporal characteristics of the clouds captured by the downwelling $\mathrm{Tb}$ at the relatively narrow band in the midinfrared region. For the spectral test, the measured $\mathrm{Tb}$ is compared with the clear-sky $\mathrm{Tb}\left(\mathrm{Tb}_{\mathrm{clr}}\right)$ which is dynamically determined as a function of $T_{\mathrm{sfc}}$ and $e$. The empirical formula for estimating $\mathrm{Tb}_{\mathrm{clr}}$ is prepared using the calculation of the radiative transfer model with the vertical profiles of temperature and humidity provided by the reanalysis of numerical weather prediction models. For the temporal test, the short-term variability of the measured $\mathrm{Tb}$ is compared with a threshold value which is also determined dynamically as a function of the measured $\mathrm{Tb}$ itself. Thus the new algorithm combines both temporal and spectral characteristics used separately or independently in the previous studies, with the dynamically determined threshold values for the separation of clear and cloudy sky. Section 2 introduces the data used for the current study along with a brief introduction of the instruments. In Sect. 3, we first introduce an empirical formula to estimate the predicted $\mathrm{Tb}_{\mathrm{clr}}$ (hereafter called $\mathrm{Tb}_{\mathrm{clr}}^{\mathrm{P}}$ ) used for the spectral test, followed by an approach to derive the dynamical threshold value for the temporal test. For the algorithm validation, we use the cloud detection data from the collocated ceilometer, which provides accurate cloud-base altitudes. The paper is summarized in Sect. 4 with planned future work for further utilization of the current work.

\section{Data}

\subsection{Radiometer data}

Downwelling infrared radiance is measured by an IRT installed on top of a ground-based microwave sounding radiometer at the Changwon Weather Station $\left(35.17^{\circ} \mathrm{N}\right.$, $128.57^{\circ} \mathrm{E} ; 37.15 \mathrm{~m}$ above sea level) of South Korea, which has been operated by the Korea Meteorological Administration (KMA) since April 2010. The microwave radiometer is manufactured by Radiometer Physics GmbH and measures downwelling microwave radiation at seven frequencies in the $22.235 \mathrm{GHz}$ water vapor absorption band (K-band) and at other seven frequencies in the $60 \mathrm{GHz}$ oxygen absorption band (V-band) (RPG, 2013). Using 14 frequency channels, various atmospheric information with a high-temporal resolution ( 2 or $3 \mathrm{~min}$ ) are derived (Solheim et al., 1998; Li et al., 1997). Recently, Won et al. (2009) also showed the possibility of deriving rainfall intensity from downwelling microwave radiances. 


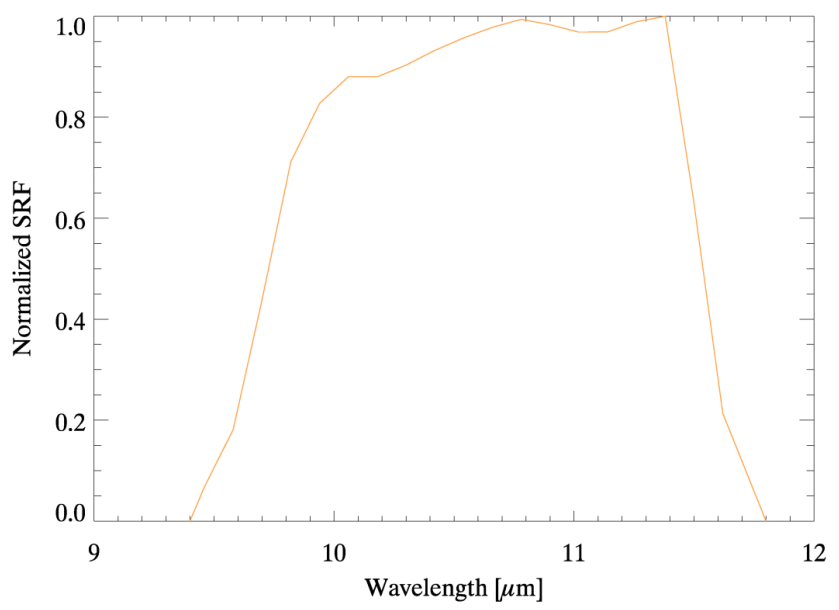

Figure 1. The spectral response function of the infrared radiometer installed on top of the ground-based microwave radiometer, at the range of 9.4-11.8 $\mu \mathrm{m}$ (Morris, 2006). The estimated center wavelength for the given spectral response function is about $10.6 \mu \mathrm{m}$.

On the other hand, the pyrometer IRT manufactured by Heitronics (KT19.85) receives the sky radiance reflected by a gold mirror (Edmund NT32-089). The reflected input radiation passes through the optical lenses and is filtered to the detector (Heitronics pyroelectric detector), which converts the radiant flux to an electrical signal. The overall spectral response function of IRT is determined from the spectral characteristics of the mirror, lenses, filter, and detector, and is shown in Fig. 1 (Morris, 2006). Although the spectral coverage spans from 9.4 to $11.8 \mu \mathrm{m}$, broad peak responses are concentrated between 10 to $11.5 \mu \mathrm{m}$, where it is characterized by weak absorption of greenhouse gases, mainly water vapor, and is away from the ozone and carbon dioxide absorption bands. The output signal is calibrated by the "chopped radiation method", utilizing frequent observations of the internal blackbody (having a pre-defined temperature) radiation between the actual target observation (Morris, 2006). The mechanical blades regularly interrupt incoming radiation from the observation target to stream the blackbody radiation into the detector. At millisecond chopping cycles, the calibration accuracy is about $0.5 \mathrm{~K}$ for different temperature precisions depending on the target temperature (Morris, 2006). The current version of IRT installed on the Changwon radiometer records measurement data every $2-3 \mathrm{~s}$ as the brightness temperature (hereafter called Tb $\mathrm{b}_{\text {IRT }}$ ), which is derived by the blackbody calibration. The actual $\mathrm{Tb}_{\mathrm{IRT}}$ in winter can record below $-70^{\circ} \mathrm{C}$, although the minimum $\mathrm{Tb}_{\text {IRT }}$ is set to be $-50^{\circ} \mathrm{C}$ because the accuracy below $-50^{\circ} \mathrm{C}$ is not practical (RPG, 2013).

Figure 2 shows a few examples of the time series of T $b_{\text {IRT }}$. The time series shows the large variability of Tb IRT $_{\text {embed- }}$ ded within the slowly varying seasonal trend, in line with the variation of atmospheric temperature and humidity. The high-frequency variability is associated with the fast vary-
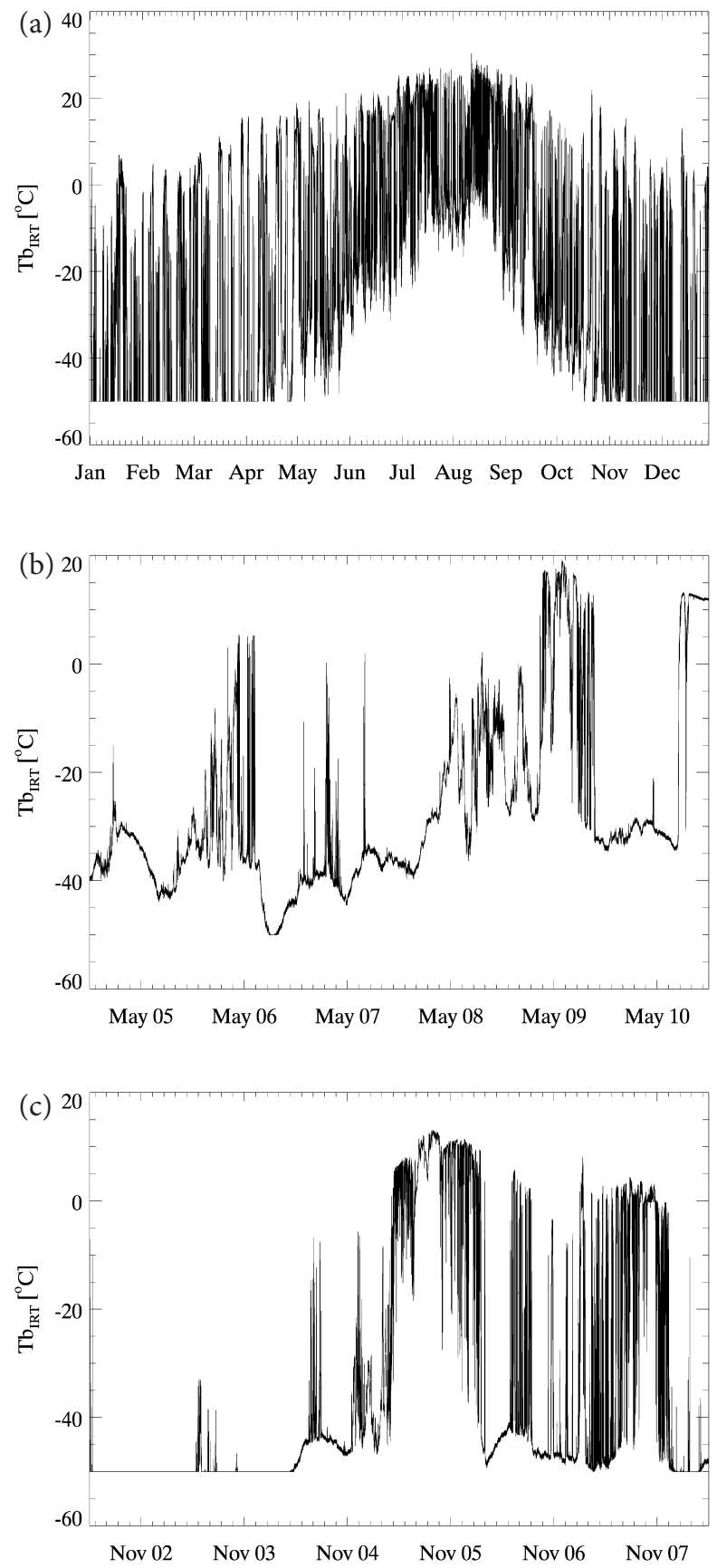

Figure 2. Time series of the measured brightness temperature of infrared radiometer ( $\mathrm{Tb}_{\mathrm{IRT}}$ ) for a period of one year (a), five days during the summer (b), and winter time periods (c) obtained at the Changwon Weather Station. The current version of IRT is set to have a lower limit of detection at $-50{ }^{\circ} \mathrm{C}$, which is evident from the data obtained during the winter period.

ing sky conditions, mostly caused by the clouds and water vapor. The usefulness and limitations of the $\mathrm{Tb}_{\mathrm{IRT}}$ data for cloud detection are explained well by Fig. 2. For example, when a cloud, even with a small optical depth, is present 
within the IRT field of view (FOV), $\mathrm{Tb}_{\mathrm{IRT}}$ increases significantly from that of the background clear sky. Thus, it could be fairly straightforward to detect the cloud presence (Thurairajah and Shaw, 2005; Brocard et al., 2011) and even to estimate the cloud-base altitude with high accuracy (Morris et al., 2006). On the other hand, as the clear-sky $\mathrm{Tb}_{\mathrm{IRT}}$ has seasonal (clearly shown in Fig. 2a) and sometimes diurnal variations (as shown in Fig. 2b and c), a fixed threshold for the cloud detection will introduce the error. For this, an objective approach to determine the threshold value taking into consideration the fast varying atmospheric conditions is required.

\subsection{Temperature and humidity data}

The best approach to take into account the varying atmospheric conditions in the cloud detection would be an estimation of instantaneous $\mathrm{Tb}_{\mathrm{clr}}$ which is compared directly with the measured $\mathrm{Tb}$. However, as the necessary information for the estimation, the vertical profiles of temperature and humidity, are not available in most cases, $\mathrm{Tb}_{\text {clr }}^{\mathrm{P}}$ is prepared using other available data. Here, we utilize the realtime $T_{\mathrm{sfc}}$ and $e$, along with an empirical formula. Although the radiometer is equipped with temperature and humidity sensors, the surface weather data obtained by an automatic weather station (AWS) at the Changwon Weather Station are used, mainly due to the malfunctioning of the humidity sensor of the radiometer during the study period. The AWS data are in the form of temperature and relative humidity $(\mathrm{RH})$ and are recorded every minute after the real-time collection, quality control, and archival processes at the KMA headquarters.

\subsection{Theoretical clear-sky Tb}

To prepare the empirical formula for $\mathrm{Tb}_{\mathrm{clr}}^{\mathrm{P}}$, we use the theoretical $\mathrm{Tb}_{\mathrm{clr}}$ using a radiative transfer model (RTM) with the input data of various atmospheric conditions. Here, the RTM simulation is done by the Modtran 5.1.2 (Berk et al., 2011) with the input vertical profiles of temperature and humidity from high resolution reanalysis data using the KLAPS (Korea Local Analysis and Prediction System) which provides hourly vertical profiles. The high resolution $\left(1 \mathrm{~cm}^{-1}\right)$ spectral radiance from the RTM simulation is converted to the simulated $\mathrm{Tb}$ through the convolution with the IRT spectral response functions (Fig. 1) and then by the inverse of the Planck function. A total of 8760 vertical profiles corresponding to a one-year time period containing the atmospheric variability of the four different seasons is utilized. One thing to note here is that we assume that all profiles are cloud free and thus we may include profiles that are from extremely wet atmospheric conditions.

\subsection{Validation data}

For the algorithm validation, we use a lidar ceilometer CL31 (Vaisala, 2004) for the quantitative assessment along with high-resolution satellite data for a qualitative comparison. The ceilometer produces the cloud fraction from 0 to 8 denoting clear and overcast, respectively, and the cloud-base altitudes at three different layers (Vaisala, 2004). As the cloud fraction is estimated using the accumulated data for a certain time period, here $20 \mathrm{~min}$, it is not suitable for the current study which requires an instantaneous estimate. Thus, instead of the cloud fraction, we use an instantaneous cloud presence derived by checking cloud-base altitudes, determining it as clear if all three cloud bases are recorded as $7.62 \mathrm{~km}$ (a situation that represents clear conditions). Here, it should be noted that the detection limit of $7.62 \mathrm{~km}$ is variable depending on the atmospheric conditions such as lower atmospheric turbidity, fog, and atmospheric density (Clothiaux et al., 2000). The instrument is installed at a distance of $15 \mathrm{~m}$, southwest from the radiometer. The ceilometer data is available with a temporal resolution of one minute and the vertical resolution of $10 \mathrm{~m}$, although it is available only after 27 September 2012.

\subsection{Pre-processing}

For the algorithm development, we first derive one-minuteaveraged $\mathrm{Tb}_{\mathrm{IRT}}$ and its standard deviation obtained from the original data with $2-3 \mathrm{~s}$ resolution, providing enough data points for a reliable statistic. The archived AWS data are in the form of $T_{\mathrm{sfc}} \mathrm{RH}$ which is converted to the surface air vapor pressure $e$ in mb using

$e=0.01 \times \mathrm{RH} \times e_{\mathrm{s}}$,

where $e_{\mathrm{S}}$ is the saturation vapor pressure corresponding to $T_{\text {sfc. }}$ An empirical formula valid for -30 to $50^{\circ} \mathrm{C}$ is used to calculate $e_{\mathrm{S}}$ for the current study (Buck, 1981):

$e_{\mathrm{s}}=6.1121 \exp \left(\frac{17.502 \times T_{\mathrm{sfc}}}{T_{\mathrm{sfc}}+240.97}\right)$.

Hourly vertical profiles of temperature and humidity from the reanalysis data are provided in $5 \mathrm{~km}$ spatial resolution. For the current study, we averaged the 4 nearest grid points to the Changwon Weather Station and retrieved data from 1 January to 31 December 2012. The model vertical grids are reformatted for use in the RTM simulation. For the algorithm development, the one-minute data of AWS and IRT are averaged for $30 \mathrm{~min}$ to match with the model reanalysis data. For the validation, we use the minute data of IRT, AWS, and the ceilometer from 1 January to 30 June 2013 when both the ceilometer and radiometer data are available. The total number of data points is 237963 . 


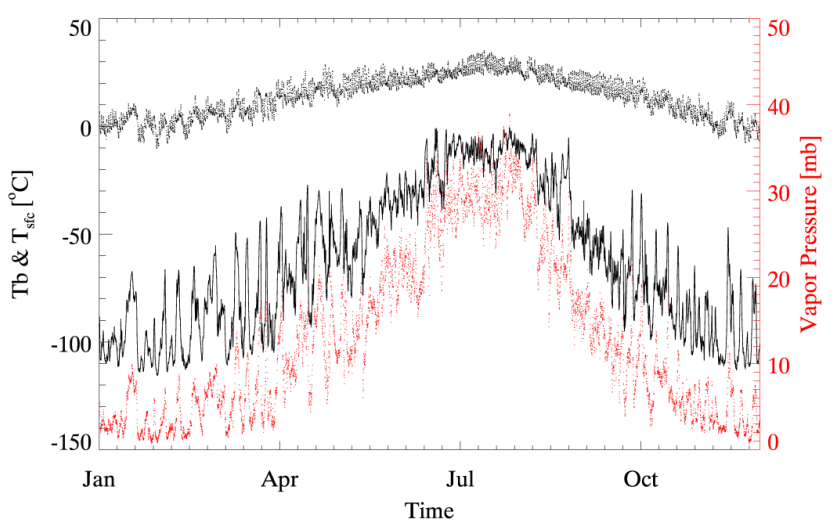

Figure 3. Time series of the simulated Tb (black solid line) along with $T_{\text {sfc }}$ (the surface air temperature; black dotted line, both temperature scales are on the left) and $e$ (the surface water vapor pressure; red dotted line with the scale on the right) from 1 January to 31 December 2012. $T_{\mathrm{sfc}}$ and $e$ are the values at the lowest levels of the vertical profiles of temperature and humidity used for the radiative transfer calculations.

\section{Algorithm}

The new algorithm takes advantage of the optical and temporal characteristics of clouds in downwelling infrared radiation in the atmospheric window region. These characteristics are utilized by the spectral and temporal tests of the measured $\mathrm{Tb}_{\mathrm{IRT}}$. For the spectral test, $\mathrm{Tb}_{\mathrm{IRT}}$ is compared with a predicted clear sky, $\mathrm{Tb}_{\text {clr }}^{\mathrm{P}}$, obtained from an empirical formula, which is derived by two steps. For the temporal test, the temporal variability of $\mathrm{Tb}_{\text {IRT }}$ during one minute is compared with a threshold value, which varies with the atmospheric conditions and is obtained by an empirically derived formula. Detailed descriptions for the derivation of empirical formula and threshold values for each test are given below.

\subsection{Predicted clear-sky $\mathbf{T b}\left(\mathbf{T b}_{\mathrm{clr}}^{\mathbf{P}}\right)$}

Figure 3 shows time series of the simulated hourly downwelling $\mathrm{Tb}$ with the reanalysis data (hereafter called Tb $\mathrm{KLAPS}_{\text {S }}$ ) along with $T_{\mathrm{sfc}}$ and $e$. Figure 3 reveals several important characteristics of $\mathrm{Tb}_{\mathrm{KLAPS}}$, representing theoretical $\mathrm{Tb}_{\mathrm{clr}}$. Firstly, even though the cloud layer is not included in the RTM simulation, Tb $b_{\text {KLAPS }}$ varies significantly with different atmospheric conditions, similar to the actual Tb $\mathrm{b}_{\text {IRT }}$. The value can be as cold as $-110^{\circ} \mathrm{C}$ during the cold and dry winter period, while it can rise to $-10^{\circ} \mathrm{C}$ during the summer period, resulting in about a $100^{\circ} \mathrm{C}$ difference between the two extremes. A significant variation of T $b_{K L A P S}$ is also evident even during a short time period within the same season, especially during the cold season. For example, $\mathrm{Tb}_{\mathrm{KLAPS}}$ varies by more than $40^{\circ} \mathrm{C}$ during mid January, mainly due to the sudden changes in $e$ along with $T_{\text {sfc }}$.

On the other hand, the variations of Tb $b_{\text {KLAPS }}, T_{\mathrm{sfc}}$, and $e$ are well correlated. Although the amplitudes are quite differ- ent, the three time series vary with the same phase. Although it is not shown, it is also true that the differences between Tb $b_{\text {KLAPS }}$ and $T_{\mathrm{sfc}}$ correlate well with $e$ and the correlation further improves when $e$ is divided by $T_{\mathrm{sfc}}$. Consequently, similar to the previous studies (Brutsaert, 1975; Idso, 1981; Marty and Philipona, 2000; Dürr and Philipona, 2004; Zhnag et al., 2007; Long and Turner, 2008; Carmona et al., 2014), an empirical formula which relates the downwelling infrared radiation to the surface weather data can be derived. Depending on the spectral range and variable of interest, such as the radiance measured in the narrow window region vs. the irradiance representing the integrated flux in the whole infrared region, a slightly different formula (such as those given by Idso, 1981, Liu et al., 2013) is required.

Thus, with the several different types of the scatter plot between the different variables, such as shown in Fig. 4, which shows the relationship between Tb $\mathrm{K}_{\mathrm{KLAPS}} / T_{\mathrm{sfc}}$ and $e / T_{\mathrm{sfc}}$, several different formulas including linear, logarithmic, and quadratic relationships, have been tested. Based on the correlation characteristics and error statistics (the first two moments) for each tested variable and formula, a quadratic relation between the logarithm of $\mathrm{Tb}_{\mathrm{KLAPS}} / T_{\mathrm{sfc}}$ and $e / T_{\mathrm{sfc}}$ was found to best fit the data:

$\log \left(\frac{\mathrm{Tb}_{\mathrm{KLAPS}}}{T_{\mathrm{sfc}}}\right)=a_{0}+a_{1}\left(\frac{e}{T_{\mathrm{sfc}}}\right)+a_{2}\left(\frac{e}{T_{\mathrm{sfc}}}\right)^{2}$,

where $a_{0}, a_{1}$, and $a_{2}$ are the empirical coefficients. With the derived coefficients, the best fit $\mathrm{Tb}_{\mathrm{KLAPS}}^{\mathrm{E}}$ is given as

$$
\begin{aligned}
\mathrm{Tb}^{\mathrm{E}} \text { KLAPS } & =T_{\mathrm{sfc}} \exp \left(-0.5422+6.727 \times\left(\frac{e}{T_{\mathrm{sfc}}}\right)\right. \\
& \left.-26.53 \times\left(\frac{e}{T_{\mathrm{sfc}}}\right)^{2}\right) .
\end{aligned}
$$

The overall performance of $\mathrm{Tb}_{\mathrm{KLAPS}}^{\mathrm{E}}$ is tested by comparison with the collocated Tb $b_{\text {KLAPS }}$, as shown in Fig. 5. The scatter plot shows that most of the data are well aligned to the one-to-one line, although there are a few outliers. The accuracy estimated by the difference between $\mathrm{Tb}_{\text {KLAPS }}^{\mathrm{E}}$ and Tb $b_{\text {KLAPS }}$ is estimated to be about $6.3 \mathrm{~K}$ (one standard deviation) with a correlation coefficient of 0.98 . The difference between $\mathrm{Tb}_{\mathrm{KLAPS}}^{\mathrm{E}}$ and $\mathrm{T} b_{\mathrm{KLAPS}}$ shows no significant variation with independent variables such as Tb $b_{\mathrm{KLAPS}}, T_{\mathrm{sfc}}$ and $e$, or time. Here, it should be noted that the uncertainty and the correlation coefficient represent the fitting accuracy of the Eq. (4), not the accuracy of $\mathrm{Tb}_{\mathrm{clr}}^{\mathrm{P}}$. Nevertheless, the uncertainty is fairly small compared to the $\mathrm{Tb}$ change due to the cloud presence (demonstrated in Fig. 7 and also by Gero and Turner, 2011 and Turner, 2007).

To correctly use $\mathrm{Tb}_{\mathrm{KLAPS}}^{\mathrm{E}}$ for cloud detection, a relationship between the theoretical TbKLAPS and the measured Tb $b_{\text {IRT }}$ should be established. This is important because the two Tbs could be different, either due to the overall uncertainty in the calculation of $T b_{K L A P S}$ or due to the uncertainty 


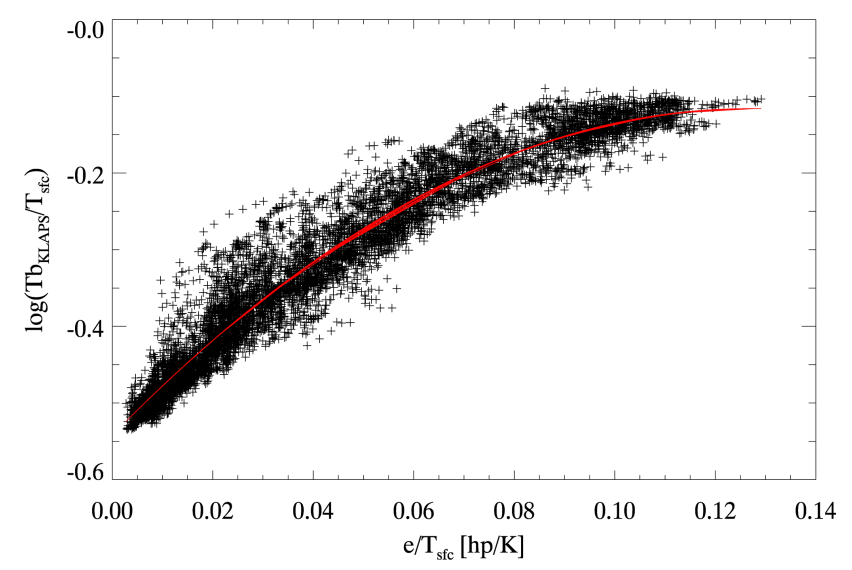

Figure 4. Simulated relationship between the ratios of brightness temperature to the surface air temperature $\left(\mathrm{Tb}_{\mathrm{KLAPS}} / T_{\mathrm{sfc}}\right)$ and the ratio of water vapor pressure to the surface air temperature $\left(e / T_{\mathrm{sfc}}\right)$. The number of data points is 8760 (hourly data for one year). The $\mathrm{Tb}$ KLAPS $/ T_{\text {sfc }}$ value increases rapidly with the increase of $e / T_{\mathrm{sfc}}$ due to the increased contribution of surface air in the downwelling radiation. When the $e / T_{\mathrm{sfc}}$ value reaches about 0.09 , the $\mathrm{T} b_{\text {KLAPS }} / T_{\text {sfc }}$ value does not vary significantly because the wavelength region is the atmospheric window region (contribution from upper air is always there).

associated with the instrument calibration. For comparison with the hourly theoretical data, the high resolution $\mathrm{Tb}_{\mathrm{IRT}}$ data are degraded by taking a half-hour averaged value; the results are shown in Fig. 6. As shown in Fig. 6a, the relationship shows a large spread and irregular distribution. However, it seems that all the points fall into three different groups - two groups with heavily packed-points and one group with widely scattered points in between the two groups. A close inspection of these points leads to the conclusion that the different groups correspond to the different sky conditions. The upper group represents overcast conditions with an appreciable addition to the downwelling radiances, while the lower group is for the clear sky where the measured and estimated Tbs are similar. The widespread points in between represent broken or fast-varying cloud conditions and the measured $\mathrm{Tb}$ vary with the degree of cloud contamination.

Thus, to establish a relationship between TbKLAPS and the measured $\mathrm{Tb}_{\mathrm{IRT}}$, we select only data points with a small temporal variability (see Sect. 3.2 for details). Figure 6b shows the two resultant groups, without most of the points in between them, clearly separated from each other. The slopes between $\mathrm{Tb}_{\mathrm{IRT}}$ and $\mathrm{Tb}_{\mathrm{KLAPS}}$ for cloudy and clear conditions are different and the difference represents the differential cloud effects on the downwelling radiance. As the cloud effect on the downwelling radiance is more prominent for the cold and dry atmosphere (Morris, 2006; also see Fig. 7), the difference between the cloudy and clear radiance increases with decreasing $\mathrm{Tb}_{\mathrm{IRT}}$. Another interesting relation between the $\mathrm{Tb}_{\mathrm{IRT}}$ and $\mathrm{Tb}_{\mathrm{KLAPS}}$ is that they are not linear (seemingly

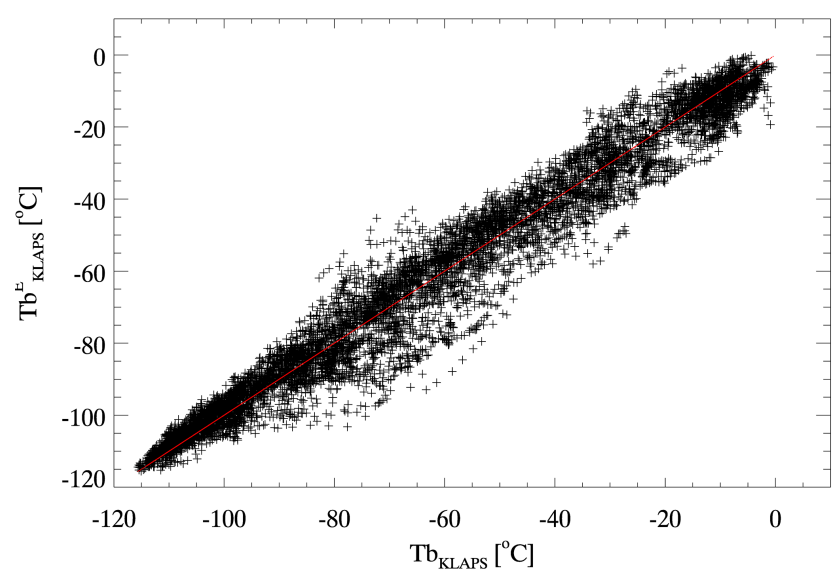

Figure 5. Scatter diagram for the estimated clear-sky $\mathrm{Tb}\left(\mathrm{Tb}_{\mathrm{KLAPS}}^{\mathrm{E}}\right)$ obtained using the surface air temperature and water vapor pressure vs. the clear-sky $\mathrm{Tb}$ by the radiative transfer calculation (red line is the one-to-one line). The root mean square difference is $6.3 \mathrm{~K}$ and the correlation coefficient is 0.98 .

quadratic) and the slope is not one, even for clear-sky conditions. It is interesting to note that the variability of $\mathrm{Tb}_{\mathrm{IRT}}$ increases at the lower $\mathrm{Tb}_{\mathrm{IRT}}$, which is thought to be related to the uncertainties in the absolute calibration of IRT. For example, an imperfect reflector (possibly due to degradation) and its uncertainty will give a larger uncertainty at lower $\mathrm{Tb}_{\text {IRT. }}$. For a quantitative assessment, further investigation is required, but this is beyond the scope of the current study.

With the limitations of the uncertainties introduced above, the relationship between Tb $b_{\text {KLAPS }}$ and the measured $\mathrm{Tb}_{\text {IRT }}$ for clear-sky conditions is established using the lower portions of the data points in Fig. 6b. In order to do that, a simple threshold is applied to Fig. $6 \mathrm{~b}$ and the remaining data points are best fitted by a quadratic formula. As Tb $b_{\text {KLAPS }}$ is obtained by assuming clear-sky conditions, the resulting relationship between $\mathrm{Tb}_{\mathrm{KLAPS}}$ and $\mathrm{Tb}_{\mathrm{IRT}}$ can be considered as the relationship between $\mathrm{Tb}_{\mathrm{clr}}^{\mathrm{P}}$ and $\mathrm{Tb}_{\mathrm{KLAPS}}^{\mathrm{E}}$. Thus, the empirical formula for the predicted clear-sky brightness temperature, $\mathrm{Tb}_{\mathrm{clr}}^{\mathrm{P}}$, to be used for clear-sky detection, is given by

$\mathrm{Tb}_{\mathrm{clr}}{ }^{\mathrm{P}}=4.39+0.865 \times \mathrm{Tb}_{\text {KLAPS }}{ }^{\mathrm{E}}+0.0032 \times\left(\mathrm{Tb}_{\mathrm{KLAPS}}{ }^{\mathrm{E}}\right)^{2}$,

where the fitting uncertainty is estimated to be $3.13^{\circ} \mathrm{C}$.

\subsection{Temporal variability}

A small variation of the cloud parameters, such as the cloud optical depth, the cloud fraction, and the cloud-base temperature, can introduce a significant variation in the measured $\mathrm{Tb}_{\text {IRT. }}$. For example, as shown in Fig. 7, even with the same cloud-base altitude and composition, the measured $\mathrm{Tb}$ differs as much as $30 \mathrm{~K}$ due to the different atmospheric conditions. Thus the downwelling radiance in cloudy conditions has much larger spatial and temporal variability than that of clear-sky conditions (Brocard et al., 2011). However, it 

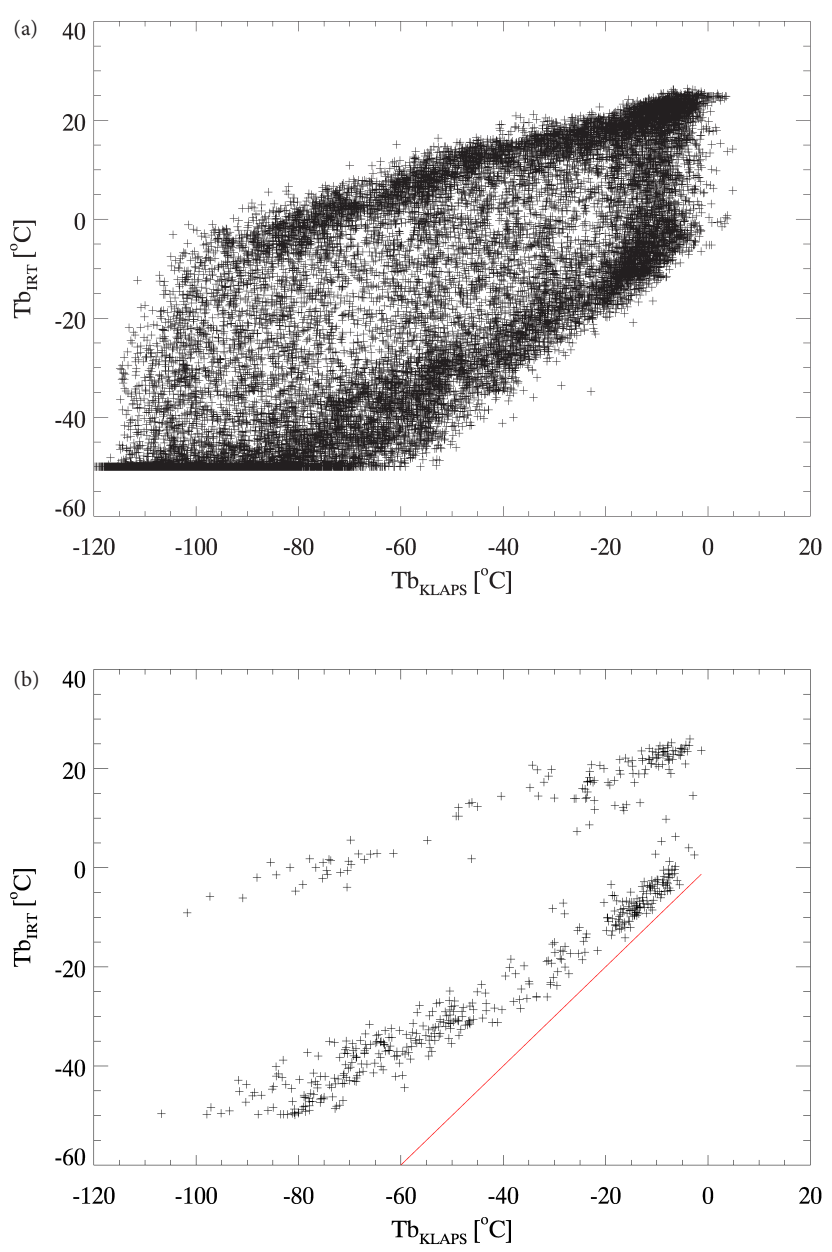

Figure 6. The relationship between the simulated clear-sky $\mathrm{Tb}$ ( $\mathrm{Tb}_{\mathrm{KLAPS}}$ ) and the measured $\mathrm{Tb}$ IRT for all conditions for one year (a), and selected cases with the Tb IRT values having a small temporal variation (b), representing overcast and clear-sky conditions (see text for details). The red line represents the one-to-one line.

should be noted that when a uniform cloud, such as a thick stratus or fog, is present, the variations are much smaller. As the ground-based IRT represents only one space dimension, i.e., the vertical space, temporal variability is used to check for both spatial and temporal variabilities. To derive a threshold value for the variability check, we first need an optimal time span to derive the temporal variability. Here, we choose one minute for three reasons: first, validation data (the ceilometer data) and auxiliary surface weather data (the AWS data) are available every minute; second, the number of available $\mathrm{Tb}_{\mathrm{IRT}}$ data points for one minute is about 25 to 30 , which provides enough statistical confidence in obtaining reliable temporal variability information; and lastly, high temporal resolution data is to be maintained as much as possible.

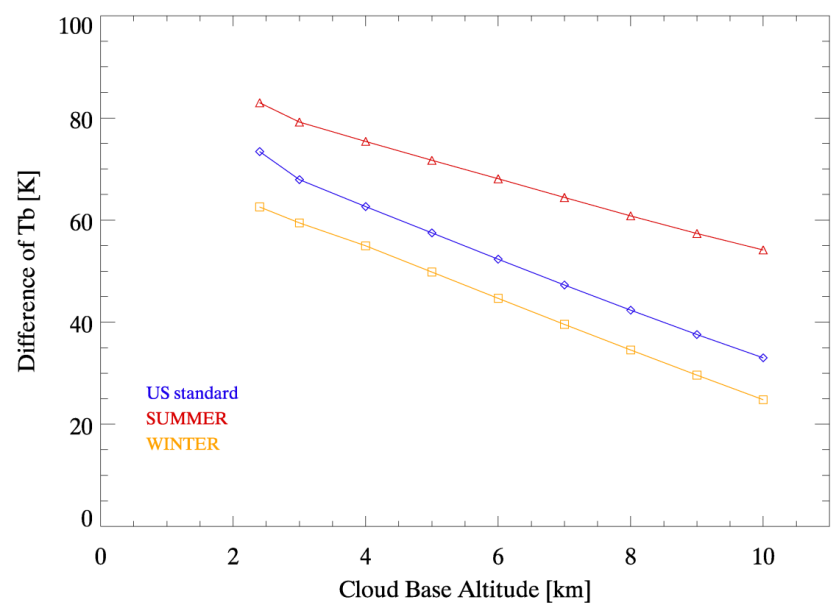

Figure 7. The simulated cloud effects to the downwelling radiance (brightness temperature difference between cloud and clear cases) as a function of the different cloud altitudes with different atmospheric profiles. Used cloud type is altocumulus given in Modtran 5.2 with the thickness of $600 \mathrm{~m}$. The high resolution spectral data are convolved with the spectral response function to give the band averaged contribution value and brightness temperature.

Figure 8 shows the time series of the averaged $\mathrm{Tb}_{\mathrm{IRT}}$ over one minute and its standard deviation $\left(\sigma_{1 \mathrm{~min}}\right)$ for $48 \mathrm{~h}$ for the summer, fall, and winter seasons. Indeed, the temporal variability $\left(\sigma_{1 \mathrm{~min}}\right)$ clearly indicates cloud presence, showing a larger $\sigma_{1 \mathrm{~min}}$ for cloudy conditions, which are also characterized by the highly variable and relatively warm $\mathrm{Tb}_{\mathrm{IRT}}$. On the other hand, seemingly clear periods with a uniform and relatively cold $\mathrm{Tb}_{\mathrm{IRT}}$ are characterized by much smaller $\sigma_{1 \mathrm{~min}}$. From careful inspection of other time periods (that are not shown in Fig. 8), we conclude that temporal variability can be used for cloud discrimination, as suggested by others (Morris et al., 2006; Dürr and Philipona; 2004; Brocard et al., 2011). However, we also found that the threshold value which separates the cloudy sky from the clear sky should be carefully selected. In particular, when we compare the $\sigma_{1 \text { min }}$ for clear-sky conditions among the three different seasons, its variability and magnitude depend significantly on the season. As can be seen in Fig. 8, $\sigma_{1 \text { min }}$ for the clear data during the summer (such as 4 August) shows a smaller and less variable distribution compared with that during the winter (such as 6 November).

Thus, to check any seasonal dependence of $\sigma_{1 \text { min }}$ for clearsky conditions, the variability of $\sigma_{1 \text { min }}$ during one year is investigated. To select enough data but also ensure that only the clear-sky data are selected, we estimate an hourly average of $\sigma_{1 \mathrm{~min}}$ and its standard deviation $\left(\sigma_{1 \mathrm{~h}}\right)$ and then select data with a small $\sigma_{1 \mathrm{~h}}$. Figure 9 shows the relationship between the hourly average of $\sigma_{1}$ min as a function of the hourly averaged $\mathrm{Tb}_{\text {IRT }}$ for the cases with a $\sigma_{1 \mathrm{~h}}$ value of less than 0.03 (this value is empirically selected, although the resulting coefficients in Eq. (6) are not very sensitive to the threshold value 

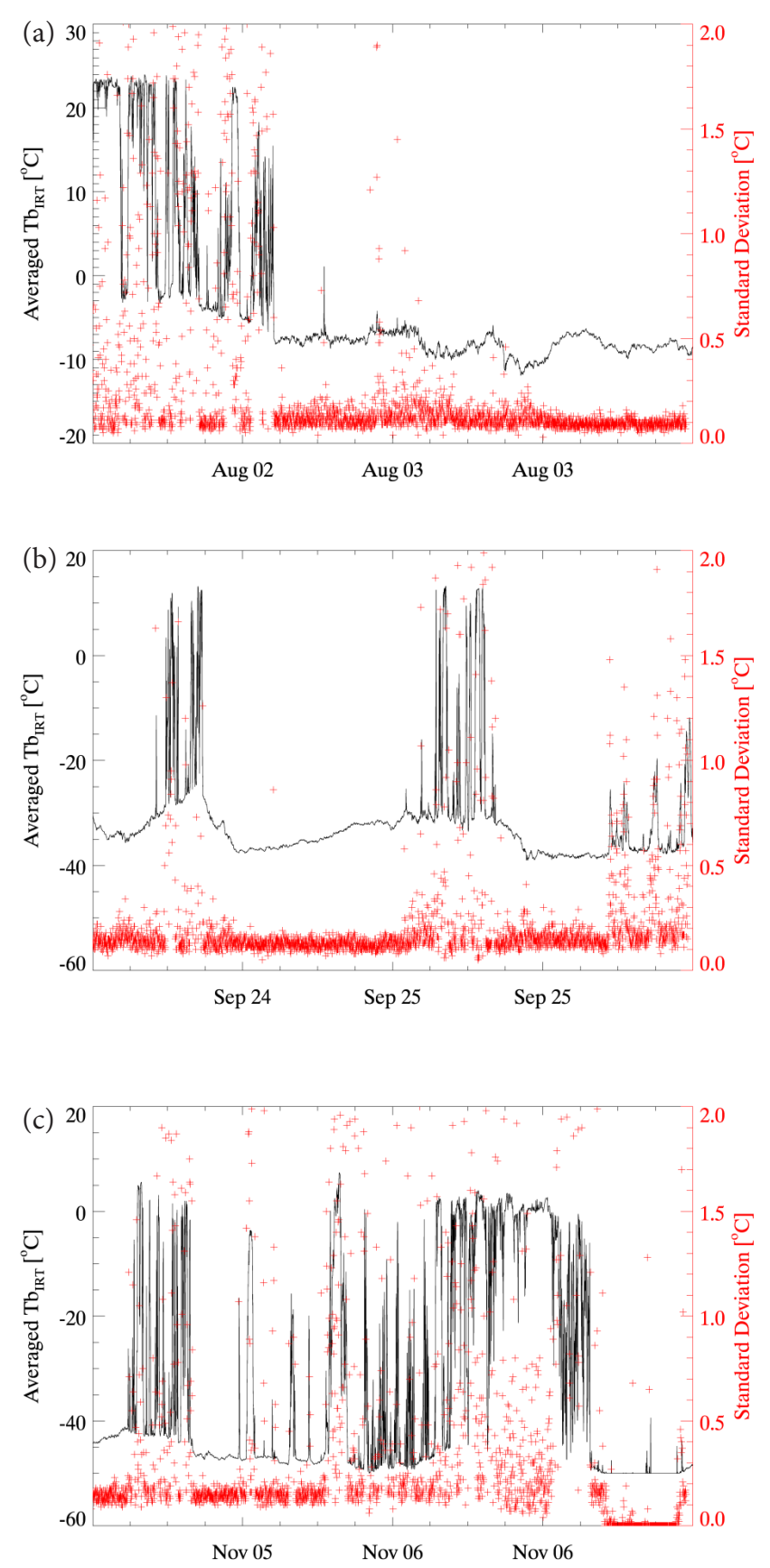

Figure 8. Time series of one-minute averaged $\mathrm{Tb}_{\text {IRT }}$ (black solid line, reference scale on the left) and its standard deviation (red cross, reference scale on the right) for $48 \mathrm{~h}$ during the summer (a), the fall (b) and the winter (c) periods. Time duration with relatively cold and homogeneous TbIRT is well represented by the relatively small and stable value of the standard deviation.

used). The hourly averaged $\sigma_{1 \text { min }}$ decreases with increasing $\mathrm{Tb}_{\mathrm{IRT}}$, consistent with Fig. 8, which shows a smaller $\sigma_{1 \mathrm{~min}}$ for the summer period (a higher $\mathrm{Tb}_{\mathrm{IRT}}$ ) and vice versa. Thus, the seasonal dependence of the $\sigma_{1 \mathrm{~min}}$ is mainly due to variations of the measured $\mathrm{Tb}_{\mathrm{IRT}}$. One of plausible causes of this

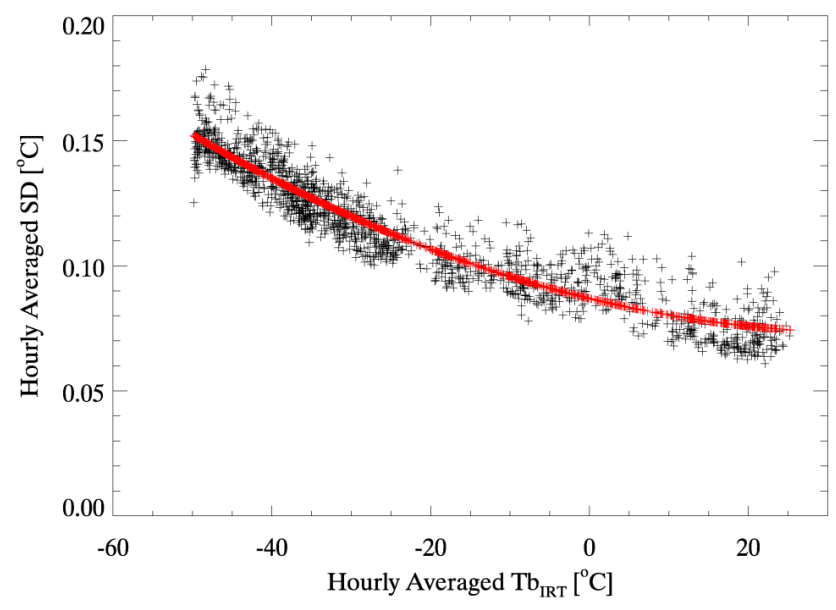

Figure 9. The relationship between the hourly averaged standard deviation and the hourly averaged Tb $\mathrm{b}_{\mathrm{IRT}}$. The red crosses are the relationship representing the best fit quadratic equation.

dependence is the difference in instrument precision (or noise performance), which is reported to be 1.1 and $0.45 \mathrm{~K}$ at 223 and $293 \mathrm{~K}$, respectively (Morris, 2006).

Based on Fig. 9, the relationship between $\mathrm{Tb}_{\mathrm{IRT}}$ and the $\sigma_{1 \text { min }}$ for clear sky $\left(\sigma_{\text {clr }}^{\mathrm{E}}\right)$ could be best fit with a quadratic formula

$\sigma_{\mathrm{clr}}^{\mathrm{E}}=0.087-7.68 \times 10^{-3} \times \mathrm{Tb}_{\mathrm{IRT}}+1.08 \times 10^{-5} \times \mathrm{Tb}_{\mathrm{IRT}}{ }^{2}$.

Here, the $\mathrm{Tb}_{\mathrm{IRT}}$ is the one-minute averaged value in Celsius and the fitting uncertainty with the hourly averaged variability is about $0.008^{\circ} \mathrm{C}$.

\subsection{Overall flow chart}

With the spectral and temporal characteristics described in the previous sections, the overall flow for the detection algorithm is schematically summarized in Fig. 10. The algorithm applies to data for every minute just after a collection of one minute's worth of IRT data and surface weather data. For the spectral test, $\mathrm{Tb}_{\mathrm{clr}}^{\mathrm{P}}$ is prepared by using $T_{\mathrm{sfc}}$ and $e$ from the AWS using Eq. (4), followed by Eq. (5). If the difference between $\mathrm{Tb}_{\mathrm{IRT}}$ and $\mathrm{Tb}_{\mathrm{clr}}^{\mathrm{P}}$ is larger than the threshold value, it is considered to be cloud contaminated. For the temporal test, one-minute IRT data are averaged to give the averaged $\mathrm{Tb}_{\text {IRT }}$ and $\sigma_{1 \mathrm{~min}}$. The measured $\sigma_{1 \mathrm{~min}}$ is then compared with $\sigma_{\mathrm{clr}}^{\mathrm{E}}$ obtained by Eq. (6). If the difference is larger than the threshold value, it is considered to be cloudy data. Finally, the data are determined as cloud-free only when both the spectral and temporal tests identify the measured $\mathrm{Tb}_{\mathrm{IRT}}$ as clear-sky data.

Here, the final question about the algorithm is "how do we choose the threshold values?" For the spectral test, the uncertainty associated with the $\mathrm{Tb}_{\text {clr }}^{\mathrm{P}}$ preparation could be used as the criterion. It is estimated by the combination of the uncertainties in the derivation of $\mathrm{Tb}_{\mathrm{KLAPS}}^{\mathrm{E}}$ (Eq. 4; considered the random uncertainty) and in the connection between $\mathrm{Tb}_{\mathrm{clr}}^{\mathrm{P}}$ and 


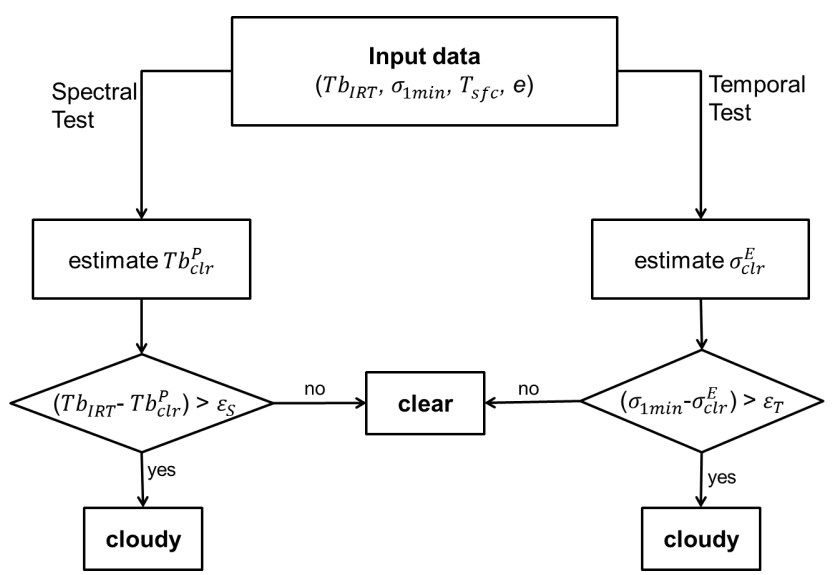

Figure 10. Flow chart of the cloud detection algorithm using the measured $\mathrm{Tb}_{\mathrm{IRT}}$ along with the $T_{\mathrm{sfc}}$ and $e$ from the automatic weather station for every minute. The estimated clear-sky $\mathrm{Tb}\left(\mathrm{Tb}_{\mathrm{clr}}^{\mathrm{P}}\right)$ and temporal variability $\left(\sigma_{\mathrm{clr}}^{\mathrm{E}}\right)$ are obtained by the Eqs. (5) and (6), respectively. The threshold values of $\varepsilon_{\mathrm{S}}$ (for spectral test) and $\varepsilon_{\mathrm{T}}$ (for temporal test) are set to 14 and $0.18 \mathrm{~K}$, respectively.

$\mathrm{Tb}_{\mathrm{KLAPS}}^{\mathrm{E}}$ (Eq. 5; considered the systematic uncertainty). As the two processes are considered as independent, the overall uncertainty (one standard level) in the determination of $\mathrm{Tb}_{\text {clr }}^{\mathrm{P}}$ is estimated to be $\sqrt{6.3^{2}+3.13^{2}}=7.0 \mathrm{~K}$. Thus, for the spectral test, we apply twice the standard deviation value as the threshold based on two factors: the cloudy data show much higher $\mathrm{Tb}_{\text {IRT }}$ than the clear data and the cases giving the less prominent signal could be filtered out by the temporal test. On the other hand, the uncertainty associated with the temporal variability is relatively straightforward, which is obtained from the fitting process. As the estimated variability is fairly small, about $0.06 \mathrm{~K}(0.008 \times \sqrt{60})$, we use $0.18 \mathrm{~K}(3 \times 1-\sigma)$ as our threshold value.

\subsection{Validation}

Figure 11 shows the original time series of $\mathrm{Tb}_{\mathrm{IRT}}, \mathrm{Tb}_{\mathrm{clr}}^{\mathrm{P}}$, and $\sigma_{1 \mathrm{~min}}$, and the algorithm results. The time period is selected to present the characteristics of the algorithm when cloud detection is more problematic due to increased clear-sky Tb IRT $_{\text {. }}$ Overall, $\mathrm{Tb}_{\mathrm{clr}}^{\mathrm{P}}$ is in good agreement with the clear-sky Tb $\mathrm{b}_{\mathrm{IRT}}$, which corresponds to the data measured between 15:10 to about 16:10 UTC (clear sky is confirmed by other observation data such as ceilometer and satellite images, not shown). In the current case, $\mathrm{Tb}_{\text {clr }}^{\mathrm{P}}$ is slightly cooler than the clear-sky Tb $b_{\text {IRT }}$ by about $7 \mathrm{~K}$, which is much smaller than the threshold value used for the clear-sky detection. In addition, the temporal variability is in good agreement with the overall feature of Tb $b_{\text {IRT }}$, i.e., it increases with increasing $\mathrm{Tb}_{\text {IRT }}$. The detection results are also as expected. For example, as can be seen for the time period from 17:40 to 18:30 UTC, the data are determined as cloud contaminated by both spectral and temporal tests, while the data from about 18:30 to 19:00 UTC are de-

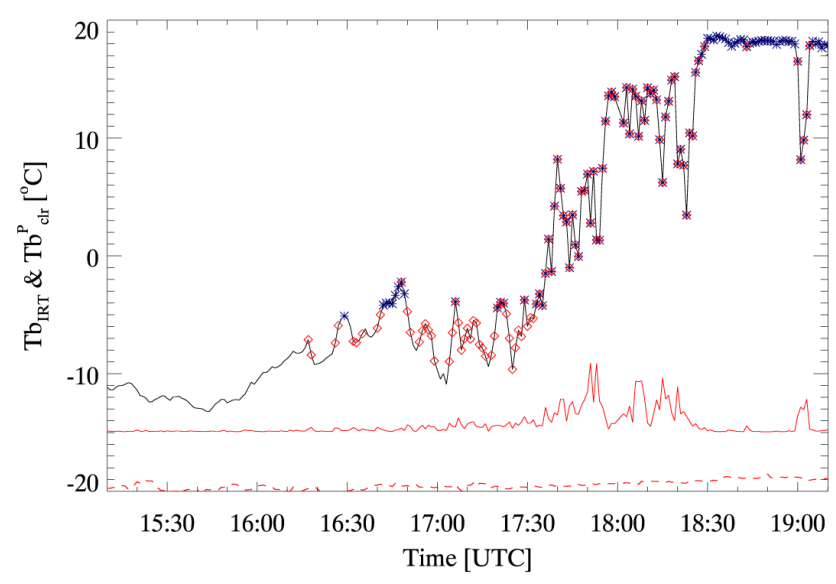

Figure 11. Time series of $\mathrm{Tb}_{\mathrm{IRT}}$ (black solid line) along with the predicted clear-sky $\mathrm{Tb}\left(\mathrm{Tb}_{\mathrm{clr}}^{\mathrm{P}}\right.$; red dashed line) and $\sigma_{1 \text { min }}$ (red solid line; for clarity, value $-15^{\circ} \mathrm{C}$ is added to the original value), for about $3 \mathrm{~h}$ of 27 June 2013. Symbols blue $*$ and red $\diamond$ denote data points classified as cloudy data determined by the spectral test and temporal test, respectively. Data points with both $*$ and $\diamond$ are the points detected as cloudy by both tests.

termined as cloudy by the spectral test alone. On the other hand, during a few occasions such as at around 16:20 UTC and the time period between 16:50 and 17:30 UTC, the cloud presence is detected by temporal variability only (except a few occasions when both tests detect). Thus, most thick and uniform clouds are identified by the spectral test, while the highly variable broken clouds are mostly identified by the temporal test. On the other hand, the edges of the advancing thick clouds are detected by both the spectral and temporal tests, as exemplified by the time period between 17:40 and 18:30 UTC.

For an objective validation, the collocated ceilometer data from 1 January to 30 June 2013 are directly compared with the IRT results, with the consideration of several factors for a direct comparison. For example, the two instruments are not looking at the exact same target at the same time. This is due to two factors. First of all, the IRT field of view is much larger than that of the ceilometer, 1.0 vs. $0.064^{\circ}$, which implies a greater possibility of cloud contamination. Secondly, the two instruments are not located exactly at the same location, the distance between the ceilometer and the IRT is about $15 \mathrm{~m}$. Thus, the two causes introduce a target-offset issue which will be important for fast-moving clouds with broken-sky conditions. Another important characteristic that should be kept in mind is that there is a well known detection limit of the ceilometer. The current version of the CL-31 has the known limit of $7.62 \mathrm{~km}$. Thus, for high clouds it would be quite normal for the IRT to detect clouds while the ceilometer would not. An example case will be given later.

The comparison results are summarized in the contingency table (Table 1) which is prepared with the total of 237963 pairs of $1 \mathrm{~min}$ IRT and ceilometer data. The 
Table 1. Contingency table for cloud detection by the infrared pyrometer (IRT) and ceilometer. The estimated proportion of correctness is $88.3 \%$ and the probability of detection is $90.8 \%$.

\begin{tabular}{|c|c|c|c|}
\hline & & \multicolumn{2}{|c|}{ Ceilometer result } \\
\hline & & Cloud & Clear \\
\hline \multirow{2}{*}{ IRT result } & Cloud & $\begin{array}{r}\text { Hit } \\
(82772)\end{array}$ & $\begin{array}{r}\text { False alarm } \\
\qquad(19551)\end{array}$ \\
\hline & Clear & $\begin{array}{l}\text { Misses } \\
(8373)\end{array}$ & $\begin{array}{r}\text { Correct negative } \\
(127267)\end{array}$ \\
\hline
\end{tabular}

estimated detection accuracy (ratio of the hit and the corrective negative to the total case) is $88.3 \%$, which is quite comparable with or better than results from other similar infrared instrumentations. For example, Feister et al. (2010) showed that cloud detection from a sky scanner coincides with the result from a whole sky imager for about $90 \%$ of cases. They also showed that the comparison is better for low clouds than for high clouds ( 92.2 vs. $85 \%$ accuracy) and attributed the difference to the difference in the detection method. On the other hand, a better validation parameter might be the probability of detection (POD) in view of the limitation that the ceilometer has. From Table 1, the estimated POD for all cases is $90.8 \%$, which is much better than a previous result (Sutter et al., 2004). They compared the results derived from infrared irradiance along with the surface temperature and humidity to the synoptic observation and found $80 \%$ of the probability of detection. As attributed by the authors, the misses are mainly due to the presence of strong inversions, thin high clouds, and dry haze which are not significant sources of error for current approach.

Also, as shown in Table 1, more than 2 / 3 of the discrepancies (misses and false alarms) are due to false alarms. A close inspection of the comparison results reveals two representative types of discrepancies, as shown in Fig. 12: one type is due to highly variable sky conditions along with the instrument configuration, and another type is due to the presence of high clouds. Figure 12a shows the time series of $\mathrm{Tb}_{\mathrm{IRT}}$ (2 October 2012) and the cloud-base altitude (for the lowest cloud) obtained from the ceilometer showing the different comparison results. In this specific case, there seems to be a time lag between the ceilometer measurement and the IRT measurement (IRT leading the ceilometer by one minute). For example, at about 04:02 UTC (red triangle), the Tb IRT time series (and the standard deviation, not shown) indicates cloudy conditions, while the cloud-base altitude is estimated to be $7.62 \mathrm{~km}$ (clear conditions), resulting in the false alarm. On the other hand, at about 04:40 UTC when the Tb IIRT $_{\text {time }}$ series clearly indicates clear-sky conditions, the cloud-base altitude is estimated to be about $2 \mathrm{~km}$, resulting in the misses. Thus, during the time period given by the two cases, all data seems to be shifted by one minute. This kind of discrepancy
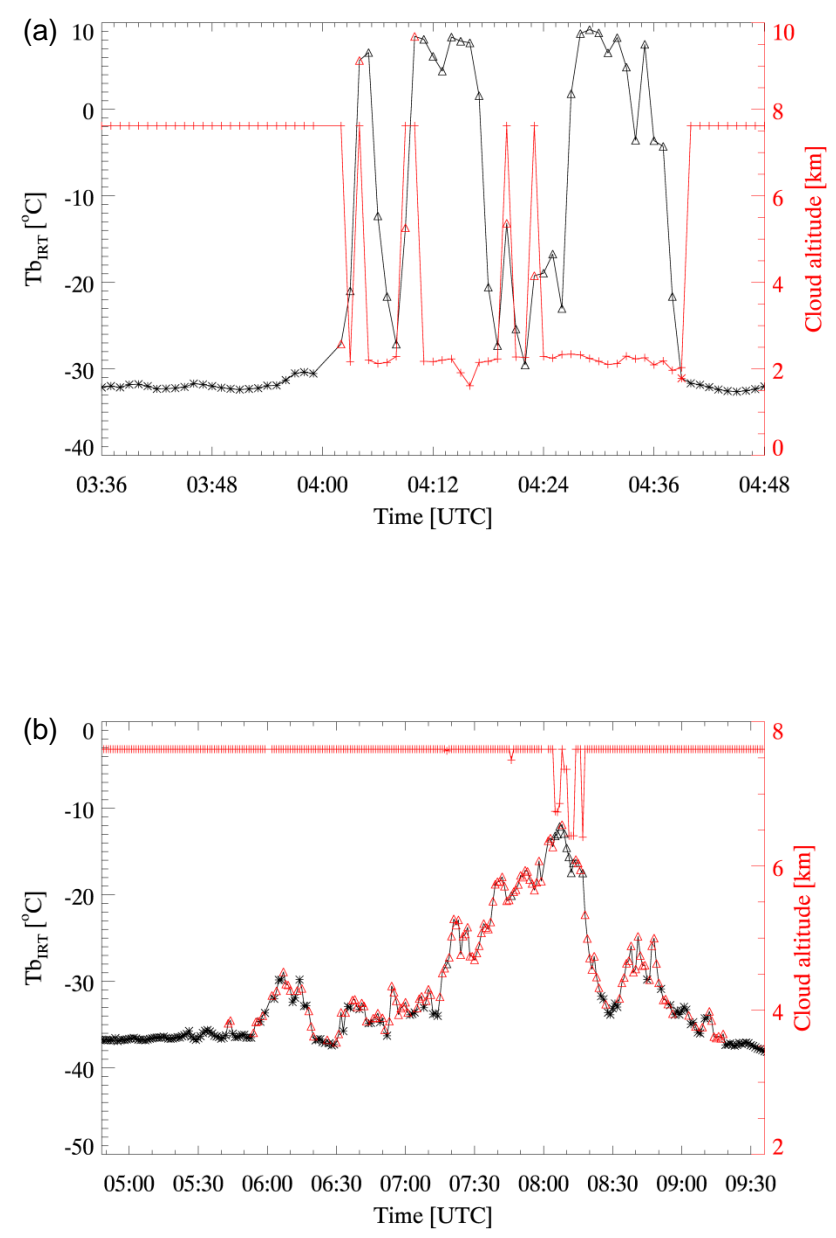

Figure 12. Two representative cases for characterization of the comparison of cloud detection and cloud-base altitude (red crosses) between IRT and ceilometer. The red symbols indicate the discrepancy cases (stars and triangles represent misses and false alarms, respectively). On the other hand, the black stars and triangles represent the successful cases. Panel (a) represents the highly variable sky conditions on 2 October 2012 and (b) exemplifies the uniform high-cloud conditions obtained on 28 March 2013.

between the two instruments could be generated by the aforementioned differences such as the differences in field of view and the distance between the two instruments.

The second representative type exemplified by Fig. 12b is for the case when high clouds are present. This is the main cause of the relatively large number of false alarms and is due mainly to the detection limit of the ceilometer. To make sure that this is indeed the case, we check high resolution satellite images obtained by COMS (communication, oceanography, and meteorological satellite), as shown in Fig. 13. In comparison with Fig. 12b, the satellite images confirm our understanding of the characteristics of the IRT and ceilometer measurements. First of all, during the time period between about 05:00 and 09:30 UTC, except for the short period between about 07:50 and 08:20 UTC, the 
05:45 UTC

06:00 UTC

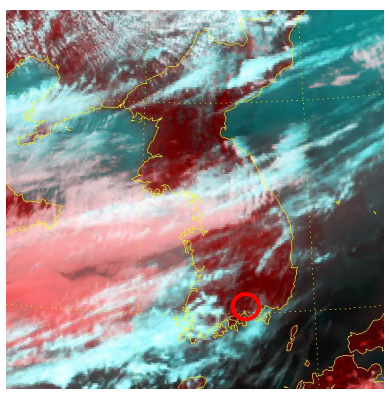

06:30 UTC

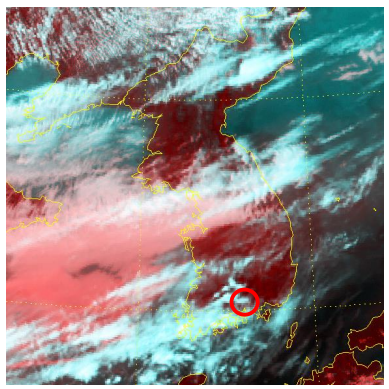

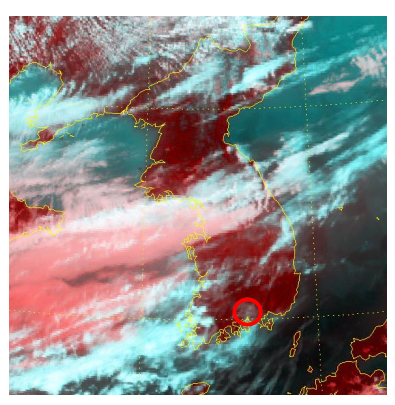

07:30 UTC

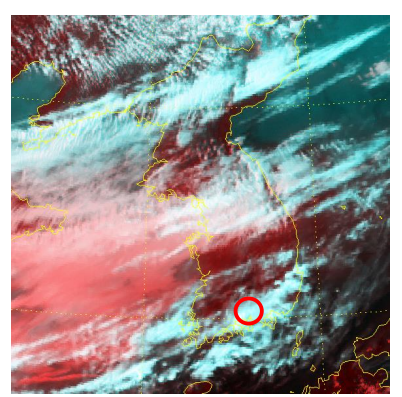

08:15 UTC

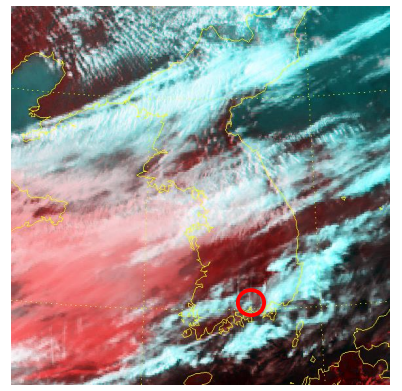

09:15 UTC

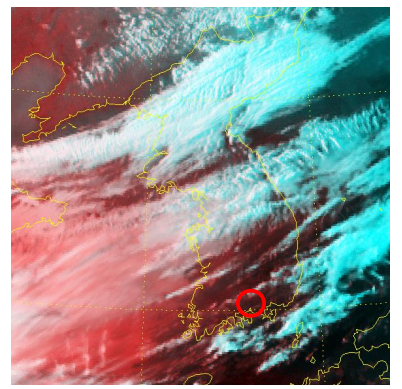

Figure 13. False color composite image (using visible, infrared window, and water vapor images) for the time used in the closer comparison of the IRT and the ceilometer. The time sequence images clearly show the approaching high clouds and a glimpse of thickening clouds over the observation station (located around the center of the red circle).

ceilometer reports no appreciable clouds other than two short periods of high clouds, while the satellite images and IRT show clear signs of a significant amount of cloud. For example, at 06:00 UTC when high clouds begin to cover the site, the composite image shows a white/gray patch (interpreted as cold and high clouds based on the visible and water vapor images) over the site, which is detected at IRT with the increase of the measured $\mathrm{Tb}_{\mathrm{IRT}}$ (about $5^{\circ} \mathrm{C}$, which results in cloud detection by the temporal variability). More clearly, at 07:30 UTC, the site is clearly covered with clouds and the measured $\mathrm{Tb}_{\text {IRT }}$ shows an appreciably higher value (about $15^{\circ} \mathrm{C}$ ) compared to the $-36^{\circ} \mathrm{C}$ of the clear-sky value recorded a few hours earlier. On the other hand, from 08:00 to $08: 18 \mathrm{UTC}$, the ceilometer detects high clouds as low as about $6.5 \mathrm{~km}$, as confirmed by the IRT and the satellite im- age. Although it is not definite, the satellite image taken at 08:15 UTC shows slightly more whitish cloud, which is located over the site, implying increased thickness and lowered cloud altitude, which are also detected by the ceilometer. After 09:15 UTC, all three data sets report no appreciable amount of cloud.

Through comparison with the satellite images, it seems that the IRT measurement is more effective than the ceilometer for high-cloud detection. To make sure that the quantitative validation results are indeed altitude-dependent, the probability of detection is estimated based on the different cloud-base altitude of the ceilometer. For low clouds (base altitude from 0 to $3 \mathrm{~km}$ ), the probability of detection is $93.8 \%$ $(59187 /(59187+3897))$, while it reduces to $90.3 \%$ for $\mathrm{mid}$ clouds (base altitude ranging $3 \mathrm{~km}$ to $5 \mathrm{~m}$ ), and is further reduced to $82.8 \%$ for high clouds (base altitude higher than $5 \mathrm{~km}$ ). This altitude dependence is quite similar to the previous study by Feister et al. (2010).

Finally, the algorithm performance is checked for the cases of strong thermal inversion. The cases are found from the vertical profiles of temperature and humidity, obtained by rawinsonde launched at the Changwon station. As the rawinsonde is launched for research purposes, data availability is not regular or continuous. Nevertheless, we could identify cases with a strong inversion and could select cases that were free from cloud influence. Figure 14 shows such a case with a skew-T log-P diagram on 6 March 2013, along with the time series of $\mathrm{Tb}_{\text {IRT }}$ similar to that in Fig. 11 and satellite images taken around the time of radiosonde observation. From the ceilometer data, satellite images, and synoptic observation (not shown), there is no significant cloud presence near the site. Similarly, the $\mathrm{Tb}_{\text {IRT }}$ time series clearly indicates a clear sky during the radiosonde observation period with a few occasional cloud presences, probably due to the effect of clouds that had passed north of the observation station, as shown in the satellite images. Although the measured Tb $\mathrm{b}_{\text {IRT }}$ increases slightly after around 00:00 UTC, it is not significant and the value is quite close to $\mathrm{Tb}_{\mathrm{clr}}^{\mathrm{P}}$. Thus, overall, the new algorithm is not sensitive to the strong inversion layer, even near the ground. This is mainly due to the spectral range that the IRT uses, as anticipated from the results of the theoretical radiative transfer calculation.

\section{Summary}

The detection of the cloud signal in the measured downwelling radiance of a ground-based microwave radiometer is an important task for characterization of the measured radiance and for further utilization of the radiance data. Here, we introduce a simple algorithm to detect cloud presence in the field of view of a ground-based microwave sounding radiometer, which could be used for real-time applications. The algorithm requires the measured downwelling radiance obtained from an infrared pyrometer installed on 

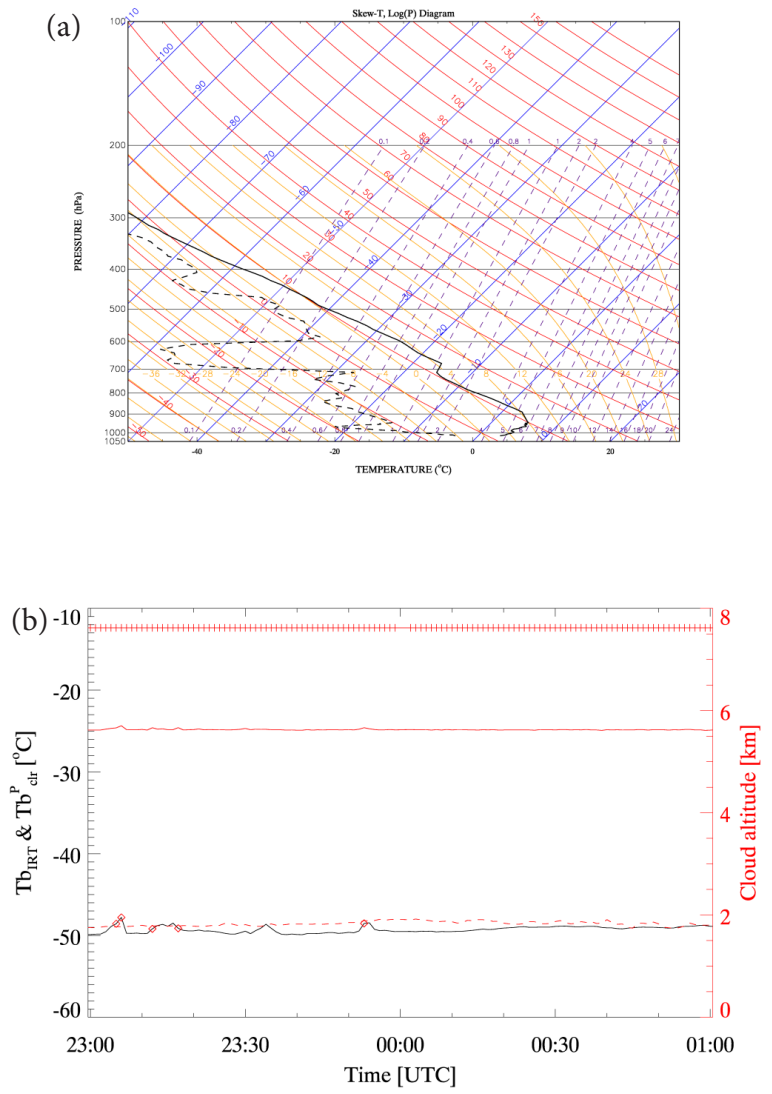

(c) 2013.03.05.23:45 UTC

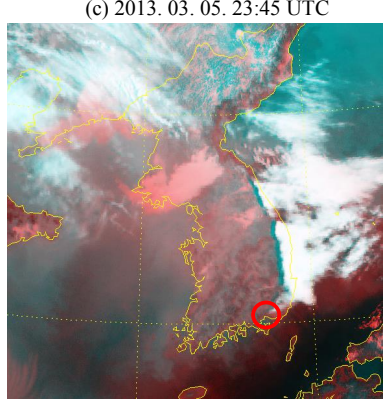

(d) 2013.03.06.00:00 UTC

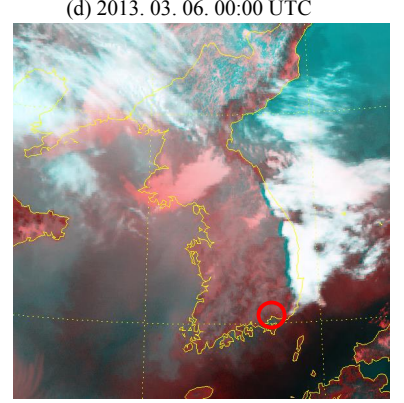

Figure 14. Vertical profiles of temperature (black solid line) and dew point temperature (black dashed line) on 6 March 2013 (a) showing a strong inversion layer from the ground to about $950 \mathrm{hpa}$, time series of TbIRT (black solid line), predicted clear-sky Tb (red dashed line), $\sigma_{1} \min$ (red solid line; for clarity, value $-25^{\circ} \mathrm{C}$ has been added to the original value), and cloud-base altitude ( + ; scale is on the right) from the ceilometer (b), and color composite satellite images for 23:45 UTC on 5 March 2013 (c) and 00:00 UTC on 6 March 2013 (d), showing passing of the cloud edge through the north of observation station.

top of the radiometer, along with real-time surface weather data including surface air temperature and humidity data. The necessary empirical formulas and relationship among the variables and threshold values for the tests are obtained from the combination of theoretical simulation and observation data obtained over a year.

The algorithm is based on the spectral and temporal characteristics of the cloud signal in the downwelling infrared radiation measured. As the clear-sky downwelling radiance at the atmospheric window region is so small, the cloud signal from most clouds are easily discernible. However, as the background clear-sky radiance varies significantly with the atmospheric temperature and humidity, a measure to account for the variation has been developed. Here, we use the theoretically calculated downwelling radiance along with the surface air temperature and water vapor pressure to derive an empirical relationship between these variables. With one year's worth of data, the fitting accuracy between the expected and calculated clear-sky brightness temperatures is about $6.3 \mathrm{~K}$, which is quite small compared to the typical cloud signal in the measured radiance. The theoretically estimated brightness temperature is further compared with actual measurement to check any discrepancies between the two and ultimately to derive an empirical formula to account for the difference with a high confidence level. For the second test, the temporal variability of the measured downwelling radiance is tested (as the radiometer views only one direction, the spatial variability is reflected in the temporal variability). To derive the temporal variability corresponding to the background uniform scenes such as a clear sky or uniform overcast cloud, the hourly averaged temporal variability is used. From the hourly averaged data, we found that the background temporal variability varies with the measured brightness temperature and derived an empirical formula relating the two variables. The two-step algorithm applies to the one-minute averaged brightness temperature with appropriate threshold values. The measured data are determined to be free only when both steps identify the data as clear data.

The algorithm performance is validated against collocated ceilometer data producing three cloud-base altitudes every minute along with the high resolution satellite data. Overall, the accuracy determined by the proportion of correctness (probability of detection) is about $89 \%$ (90.8\%), which is comparable with or better than previous studies. Among the discrepancies (IRT results are not the same as the ceilometer results), 2 / 3 of them are caused by over-detection of clouds by the IRT. By a closer inspection of the IRT and ceilometer data with high resolution satellite images, the over-detection could be represented by two cases. One case is due to highly variable cloud conditions, caused by the different measurement methods and the distance between the two instruments. The other occurred when the altitude of the cloud was beyond the detection limit of the ceilometer, while the cloud signal was strong enough to be detected by the IRT, as verified by high resolution satellite data. On the other hand, among 1 / 3 of the discrepancies caused by under-detection of clouds by the IRT, a large portion is due to the limited lower boundary of the dynamic range, $-50^{\circ} \mathrm{C}$, of the current version of IRT. To make sure that the IRT measurement is 
not affected by the inversion layer, we also check the available rawinsonde profiles and demonstrate the insensitivity of the new algorithm to the presence of inversion layers.

Overall, the new cloud detection algorithm performs well even with only a limited amount of information available. The results are comparable with the lidar ceilometer and indicate the possibility of better performance for certain situations. This is achieved mainly by the application of the predicted clear-sky $\mathrm{Tb}$ which takes into account of locationspecific relationship between surface weather data and $\mathrm{Tb}$, and by the application of sensor-specific criteria for the temporal variability of the clear-sky $\mathrm{Tb}$. The other reason for the improvement is the bandwidth of the current IRT, narrower than other broadband instruments, which amplifies the cloud signal over atmospheric signals such as those due to inversion, water vapor or haze. However, it still has room for improvement in areas such as the prediction of clear-sky radiance and refinement of the threshold value of the temporal test. With better theoretical clear-sky radiance, we may improve the estimates of the cloud-base altitude. Also, as indicated in the comparison between theoretical and measured radiances, a detailed investigation of the calibration accuracy of the IRT is necessary, paying particular attention to any degradation or variation of the reflectivity of the reflector. Furthermore, there seems to be considerable room for improvement by extending the dynamic range of the IRT toward the cooler temperature, especially for the colder clouds. Finally, clear-sky radiance data could be used for further characterization of the microwave radiometer.

Acknowledgements. This work is supported by the "Development and application of technology for weather forecasting (NIMR2012-B-1)" of the National Institute of Meteorological Research (NIMR). The authors are grateful to the KMA for providing the radiometer, ceilometer, and ground observation data.

Edited by: M. Kulie

\section{References}

Berk, A., Anderson, G. P., Acharya, P. K., and Shettle, E. P.:, “MODTRAN ${ }^{\circledR}$ 5.2.1 User's Manual", Spectral Sciences, INC., Burlington, MA, 69 pp., 2011.

Brocard, E., Schneebeli, M., and Matzlelr, C.: Detection of cirrus clouds using infrared radiometery, IEEE T. Geosci. Remote, 49, 595-602, 2011.

Brutsaert, W.: On a derivable formula for long-wave radiation from clear skies, Water Resour. Res., 11, 742-744, doi:10.1029/WR011i005p00742, 1975.

Buck, A. L.: New equation for computing water vapour pressure and enhancement factor, J. Appl. Meteorol., 20, 1527-1532, 1981.

Cadeddu, M. P. and Turner, D. D.: Evaluation of water permittivity models from ground-based observations of cold clouds at frequencies between 23 and $170 \mathrm{GHz}$, IEEE T. Geosci. Remote, 49, 2999-3008, doi:10.1109/TGRS.2011.2121074, 2011.
Carmona, F. R., Rivas, R., and Caselles, V.: Estimation of daytime downward longwave radiation under clear and cloudy skies conditions over a sub-humid region, Theor. Appl. Climatol., 115, 281-295, doi:10.1007/s00704-013-0891-3, 2014.

Cimini, D., Westwater, E. R., Han, Y., and Keihm, S. J.: Accuracy of Ground-Based Microwave Radiometer and Balloon-Borne Measurements During the WVIOP2000 Field Experiment, IEEE T. Geosci. Remote, 41, 2605-2615, 2003.

Clothiaux, E. E., Ackerman, T. P., Mace, G. G., Moran, K. P. Marchand, R. T., Miller, M. A., and Martner, B. E.: Objective Determination of Cloud Heights and Radar Reflectivities Using a Combination of Active Remote Sensors at the ARM CART Sites, J. Appl. Meteor., 39, 645-665, 2000.

Crewell, S. and Löhnert, U.: Accuracy of cloud liquid water path from ground-based microwave radiometery 2. Sensor accuracy and synergy, Radio Sci., 38, 8042, doi:10.1029/2002RS002634, 2003.

Dürr, B. and Philipona, R.: Automatic cloud amount detection by surface longwave downward radiation measurement, J. Geophys. Res., 109, D5, doi:10.1029/2003JD004182, 2004.

Feister,U., Möller, H., Sattler, T., Shields, J., Görsdorf, U., and Güldner, J.: Comparison of macroscopic cloud data from groundbased measurements using VIS/NIR and IR instruments at Lindenberg, Germany, Atmos. Res., 96, 395-407, 2010.

Gaussiat, N., Hogan, R. J., and Illingworth, A. J.: Accurate liquid water path retrieval from low-cost microwave radiometers using additional information from a lidar ceilometer and operational forecast models, J. Atmos. Ocean. Tech., 24, 1562-1575, 2007.

Gero, P. J. and Turner, D. D.: Long-term trends in downwelling spectral infrared radiance over the U.S. southern Great Plains, J. Climate, 24, 4831-4843, doi:10.1175/2011JCLI4210.1, 2011

Han, Y. and Westwater, E. R.: Remote sensing of tropospheric water vapor and cloud liquid water by integrated ground-based sensors, J. Atmos. Ocean. Tech., 12, 1050-1059, 1995.

Hewison, T.: 1D-VAR retrieval of temperature and humidity profiles from a ground-based microwave radiometer, IEEE T. Geosci. Remote, 45, 2163-2168, 2007.

Idso, S. B.: A set of equations for full spectrum and 8- to $14 \mu \mathrm{m}$ thermal radiation from cloudless skies, Water Resour. Res., 17, 295-304, 1981.

Klebe, D. I., Blatherwick, R. D., and Morris, V. R.: Ground-based all-sky mid-infrared and visible imagery for purposes of characterizing cloud properties, Atmos. Meas. Tech., 7, 637-645, doi:10.5194/amt-7-637-2014, 2014.

Li, L., Vivekanandan, J., Chan, C., and Tsang, L.: Microwave radiometric technique to retrieve vapor, liquid and ice, Part IDevelopment of a neural network-based inversion method, IEEE T. Geosci. Remote, 35, 224-236, 1997.

Liljegren, J. C. and Lesht, B. M.: Measurements of integrated water vapor and cloud liquid water from microwave radiometers at the DOE ARM Cloud and Radiation Testbed in the U.S. southern Great Plains, Proc. Int. Geophys. Rem. Sens. Symp., 96, 16751677, 1996.

Liu, L., Sun, X.-J., Gao, T.-C., and Zhao, S.-J.: Comparison of Cloud Properties from Ground-Based Infrared Cloud Measurement and Visual Observations, J. Atmos. Ocean. Tech., 30, 11711179, doi:10.1175/JTECH-D-12-00157.1, 2013.

Löhnert, U. and Maier, O.: Operational profiling of temperature using ground-based microwave radiometry at Payerne: 
prospects and challenges, Atmos. Meas. Tech., 5, 1121-1134, doi:10.5194/amt-5-1121-2012, 2012.

Löhnert, U., Crewell, S., Krasnov, O., O'Connor, E., and Russchenberg, H.: Advances in Continuously Profiling the Thermodynamic State of the Boundary Layer: Integration of Measurements and Methods, J. Atmos. Ocean. Tech., 25, 1251-1266, doi:10.1175/2007JTECHA961.1, 2008.

Long, C. N. and Turner, D. D.: A method for continuous estimation of clear-sky downwelling longwave radiative flux developed using ARM surface measurement, J. Geophys. Res., 113, D18206, doi:10.1029/2008JD009936, 2008.

Marty, C. and Philipona, R.: The clear-sky index to separate clearsky from cloudy-sky situations in climate research, Geophys. Res. Lett., 27, 2649-2652, 2000.

Morris, V. R.: Infrared Thermometer (IRT) Handbook, ARM TR-015, U.S. Department of Energy, 14 pp., available at: http://www.arm.gov/publications/tech_reports/handbooks/irt_ handbook.pdf?id=36, last access: 30 January 2015, 2006.

Morris, V. R., Long, C. N., and Nelson, D.: Deployment of an Infrared Thermometer Network at the Atmospheric Radiation Measurement Program Southern Great Plains Climate Research Facility, Proceedings of the Sixteenth Atmospheric Radiation (ARM ) Science Team Meeting, edited by: Carrothers, D., U.S. Department of Energy, Richland, WA, 2006.

Ohmura, A.: Physical Basis for the Temperature-Based Melt-Index Method, J. Appl. Meteor., 40, 753-761, 2001.

RPG: Instrument Operation and Software Guide - Principle of Operation and Software Description for RPG standard single-polarization radiometers, available at: http://www. radiometer-physics.de/rpg/html/Download.html (last access 30 August 2013), 2013.
Solheim, F., Godwin, J. R., Westwater, E. R., Han, Y., Keihm, S. J., Marsh, K., and Ware, R.: Radiometric profiling of temperature, water vapor and cloud liquid water using various inversion methods, Radio Sci., 33, 393-404, 1998.

Sutter, M., Dürr, B., and Philipona, R.: Comparison of two radiation algorithms for surface-based cloud-free sky detection, J. Geophys. Res., 109, D17202, doi:10.1029/2004JD004582, 2004.

Thurairajah, B. and Shaw, J. A.: Cloud statistics measured with the infrared cloud imager (ICI), IEEE T. Geosci. Remote, 43, 20002007, 2005.

Turner, D. D.: Improved ground-based liquid water path retrievals using a combined infrared and microwave approach, J. Geophys. Res., 112, D15204, doi:10.1029/2007JD008530, 2007.

Turner, D. D. and Gero, P. J.: Downwelling $10 \mu \mathrm{m}$ radiance temperature climatology for the Atmospheric Radiation Measurement Southern Great Plains site, J. Geophys. Res., 116, D08212, doi:10.1029/2010JD015135, 2011.

Vaisala, User's Guide 2004: Vaisala Ceilometer CL31, Vaisala Oyj, Helsinki, Finland, 127 pp., 2004.

Won, H.-Y., Kim, Y.-H., and Lee, H.-S.: An application of brightness temperature received from a ground-based microwave radiometer to estimation of precipitation occurences and rainfall intensity, Asia Pac J. Atmos. Sci., 45, 55-69, 2009.

Zhang, W.-X., Lu, D.-R., and Change, Y.-L.: A feasibility study of cloud base height remote sensing by simulating ground-based thermal infrared brightness temperature measurements, Chinese J. Geophys., 50, 339-350, 2007. 